\title{
Proposta de Sequência Didática para Hidrostática: Aprendizagem Ativa em Destaque no Ensino de Física
}

Alberto Silva Cid

Centro Federal de Educação Tecnológica Celso Suckow da Fonseca

Valença - RJ

Márcio Pizzi ${ }^{1}$

Centro Federal de Educação Tecnológica Celso Suckow da Fonseca

Valença - RJ

Thiago Corrêa Lacerda ${ }^{1}$

Instituto Federal de Educação Ciência e Tecnologia

Niterói - RJ

Erichardson Tarocco de Oliveira ${ }^{1}$

Centro Federal de Educação Tecnológica Celso Suckow da Fonseca

Valença - RJ

\section{Resumo}

O ensino de Ciências, por vezes, é considerado pouco estimulante pela ausência de atividades interativas, capazes de explorar aspectos experimentais e investigativos dos conteúdos. Neste sentido, este artigo propõe uma sequência didática para o ensino de Hidrostática que é norteada por três metodologias de aprendizagem ativa: PredizerObservar-Explicar, Instrução por Pares e Ensino sob Medida. A sequência foi aplicada em duas turmas do ensino médio da rede federal. Além disso, foram aplicados testes de leitura e testes conceituais a fim de verificar assimilação dos conteúdos. Para uma aferição quantitativa dos resultados, fez-se uma análise dos índices de acertos destes testes, através de relatórios gerados pelo Plickers. Por fim, os alunos ficaram mais engajados e os resultados estatísticos mostram que as três metodologias integradas permitem assimilação melhor dos conceitos e definições de Hidrostática.

\footnotetext{
${ }^{+}$Didatic Sequence Proposal for Hydrostatics: Active Learning Highlighted in Physics Teaching

* Recebido: abril de 2020. Aceito: junho de 2020.

${ }^{1}$ E-mails: asilvacid@gmail.com; marcio@rumori.com.br; thiago.lacerda@ifrj.edu.br; erifisico@yahoo.com.br
} 
Palavras-chave: Aprendizagem Ativa; Sequência Didática; Hidrostática.

\begin{abstract}
The Science Teaching sometimes is not very exciting due to the absence of interactive activities, capable of exploring experimental and investigative aspects of the contents. In this sense, this article proposes a didactic sequence for the Hydrostatic teaching which is guided by three learning methodologies: Predict-Observe-Explain, Peer Instruction, and Just-in-Time teaching. The sequence was applied to two high school classes of the federal education system. In addition, reading tests and conceptual tests were applied in order to verify assimilation of the contents. For a quantitative measurement of the results, one made an analyze of the hit rates of these tests through reports generated by Plickers. Finally, the students have became more engaged and the statistics results show that three integrated methodologies allow better assimilation of the concepts and definitions of the Hydrostatic.
\end{abstract}

Keywords: Active Learning; Didatic Sequence; Hydrostatic.

\title{
I. Introdução
}

O ensino de Ciências na educação básica privilegia, frequentemente, atividades desconectadas da realidade do educando em detrimento de atividades investigativas e experimentais capazes de realizar conexões com os universos social, tecnológico, histórico, científico e ambiental (CHAPACUZ; PRAIA; JORGE, 2004, p. 368).

A escolha das práticas docentes é influenciada, entre outros fatores, por tendências de exames que permitem o acesso às instituições de nível superior e por livros didáticos que favorecem a intensa mecanização do raciocínio (CHIQUETTO; KRAPAS, 2012, p. 177-180). Além disso, a formação docente é pouco atenta às discussões que propiciam uma mentalidade interdisciplinar (CHIQUETTO; KRAPAS, 2012, p. 186). A questão sobre como e o porquê de ensinar Ciências é fundamental e desafiadora:

[...] O que importa fomentar, e desde o início da escolaridade, é a curiosidade natural dos alunos e o seu entusiasmo pela Ciência /Tecnologia e, para tal, uma perspectiva sistêmica do conhecimento é a mais indicada. Em particular, para os mais novos, trata-se de explorar os seus saberes do dia a dia como ponto de partida, já que é por aí que os alunos mais facilmente podem reconhecer os contextos $e$, história pessoal a que eventualmente estão ligados $e$, consequentemente, aumentar a sua motivação. Trata-se de contextualizar $e$ 
humanizar a Ciência escolar (não confundir com banalizar) para que mais facilmente e mais cedo se desperte o gosto pelo seu estudo (CACHAPUZ; PRAIA; JORGE, 2004, p. 368).

A partir da problemática exposta sobre o ensino de Ciências, surge o interesse em levantar discussões sobre a importância do letramento científico como condição para gerar autonomia dos indivíduos em um mundo que predomina a linguagem científica e tecnológica. Essa autonomia pode ser desenvolvida nos espaços escolares à medida que os conteúdos sejam compreendidos como meios para desenvolver competências e habilidades, que são negligenciadas quando o conteúdo é visto como fim em si mesmo (CHAPACUZ; PRAIA; JORGE, 2004, p. 374).

Habilidades e competências inerentes ao ensino de Física são capazes de formar consciência crítica sobre informações científicas disponibilizadas no cotidiano. Algumas das habilidades podem ser elencadas: obtenção e interpretação de dados experimentais; construção e interpretação de gráficos; o uso e significado das unidades de medida; o uso e conhecimento de diferentes instrumentos de medida; a capacidade de aplicar conceitos típicos da Física em outras áreas do conhecimento (BORGES, 2002).

As habilidades podem ser articuladas através do emprego de metodologias de aprendizagem ativa. A literatura identifica mais de 20 metodologias deste tipo de aprendizagem (LOVATO et al., 2018, p.160-165; HENDERSON; DANCY; BUGAJ, 2012, p.2). Entretanto, poucos trabalhos são dedicados ao ensino médio, público alvo desse trabalho (MÜLLER et. al., 2017, p. 4-5).

Esse artigo propõe uma sequência didática norteada pelos princípios fundamentais de três dessas metodologias: Predizer - Observar - Explicar (POE) (WHITE; GUNGSTONE, 1992; CID; CORREA, 2019; SASAKI; JESUS, 2017; SANTOS; SASAKI, 2015; KIBIRIGE; OSODO; TLALA, 2014); Instrução por Pares (de PAULA; FIGUEIREDO; FERRAZ, 2020; ALVARADO; MORA; REYES, 2019; KIELT; da SILVA; MIQUELIN, 2017; ARAUJO; MAZUR, 2013); Ensino sob Medida (LEAL et. al, 2019; CUPITA, 2016).

A sequência proposta versa sobre hidrostática e está construída para criar conexões de conceitos típicos do conteúdo abordado com outras áreas do conhecimento. Além disso, o material apresentado serve de referência para os professores que pretendem inovar suas práticas pedagógicas, mas encontram limitação de recursos físicos e financeiros.

As metodologias ativas enfocam aspectos diversos do aprendizado variando do individual para o coletivo e do abstrato para o concreto. A utilização conjunta das metodologias gera uma complementaridade fortuita para os objetivos da iniciativa pedagógica. Desse ponto de vista é que está fundamentada a apresentação de uma sequência inteira de atividades ao invés do desenvolvimento de um único conceito através de uma única metodologia de aprendizagem. 
A sequência foi aplicada em duas turmas de ensino médio técnico integrado em uma instituição da rede federal de ensino. Uma das turmas possui 19 estudantes, enquanto a outra possui 29 estudantes.

Os resultados qualitativos e quantitativos obtidos nesse trabalho apontam para o fato de que o uso de metodologias de aprendizagem ativa cumpre com o papel de gerar aprendizado, engajamento e autonomia dos estudantes. Além disso, estas metodologias servem de ferramentas que permitem acessar concepções alternativas para explicação dos fenômenos e diagnosticar comportamentos dos estudantes com relação ao conteúdo, ao professor e seus pares.

\section{Referencial teórico}

Metodologias de aprendizagem ativa são fundamentadas no construtivismo. Todas elas têm o objetivo de gerar condições propícias para os alunos manifestarem seus conhecimentos prévios sobre um tema ou conceito, dialogarem em sala de aula com seus pares e expressarem os conceitos trabalhados em diferentes linguagens (DEMERCI, 2010, p. 278). A seguir são feitas observações gerais sobre as metodologias que norteiam esse artigo: o POE, a Instrução por Pares e o Ensino sob Medida.

O POE (do inglês Predict - Observe - Explain) é uma metodologia baseada no conceito de conflito cognitivo e foi criada, originalmente, para evidenciar e discutir concepções errôneas em aulas de Mecânica Clássica (WHITE; GUNGSTONE, 1992). É constituído por três etapas, conforme sugere a nomenclatura em inglês: previsão, observação e explicação.

A etapa previsão tem por objetivo favorecer a verbalização do conhecimento prévio do estudante através da proposição de situações experimentais. Por sua vez, na etapa observação é feito um experimento ou simulação pelo estudante. Por fim, na última etapa o estudante deve explicar as diferenças encontradas entre a previsão e a observação.

É importante ressaltar que deve ser estabelecido um equilíbrio no nível das questões da etapa previsão. Essa consideração decorre do fato de que situações muito fáceis ou muito difíceis geram desinteresse e impedem o surgimento do conflito cognitivo, que é essencial para a metodologia.

A metodologia conhecida como Instrução por Pares (do inglês Peer Instruction) foi criada pelo professor Eric Mazur de Havard no contexto das aulas de Mecânica Clássica, assim como o POE (MAZUR, 2015). Este método é baseado na socialização do conhecimento pelos alunos e na substituição de aulas tradicionais (expositiva) por testes de leitura, curtas exposições e testes conceituais (de PAULA; FIGUEIREDO; FERRAZ, 2020).

O ensino sob medida (do inglês Just-in-timing teaching) é baseado no conceito de aulas personalizadas. O professor envia tarefas de leitura para seus alunos e solicita que questões de sondagem sejam respondidas para averiguar o nível de entendimento do texto e a compreensão dos conceitos elaborados. As respostas das questões são enviadas, 
antecipadamente, para o professor a fim de oportunizar o planejamento das aulas de acordo com as dificuldades identificadas nas respostas às questões (SANTOS, 2016).

A Tabela 1 resume os conceitos fundamentais e as principais características para cada metodologia empregada: o POE, a Instrução por Pares e o Ensino sob Medida.

Tabela 1 - Resumo do conceito fundamental de cada metodologia e suas características.

\begin{tabular}{|c|c|c|}
\hline Metodologia & Conceito Fundamental & Características \\
\hline POE & $\begin{array}{c}\text { Conflito Cognitivo } \\
\text { (WHITE; GUNGSTONE, } \\
\text { 1992) }\end{array}$ & $\begin{array}{l}\text { 1. Formado por três etapas: previsão, observação } \\
\text { e explicação. } \\
\text { 2. O professor apresenta uma situação problema } \\
\text { e o estudante registra uma previsão de acordo } \\
\text { com seu conhecimento prévio. A situação } \\
\text { problema é materializada em forma de } \\
\text { experimento físico ou virtual. } \\
\text { 3. O estudante explica seu entendimento sobre } \\
\text { o fenômeno observado. }\end{array}$ \\
\hline $\begin{array}{l}\text { Instrução por } \\
\quad \text { Pares }\end{array}$ & $\begin{array}{l}\text { Socialização do } \\
\text { Conhecimento } \\
\text { (MAZUR, 2015) }\end{array}$ & $\begin{array}{l}\text { 1. No início de cada aula é feito um teste de } \\
\text { leitura. } \\
\text { 2. Durante as aulas são feitas exposições curtas } \\
\text { de } 10 \text { ou } 15 \text { minutos sobre tópicos do material } \\
\text { de leitura e após cada exposição são aplicados } \\
\text { testes conceituais. } \\
\text { 3. Se o índice global de acertos para os testes } \\
\text { conceituais for inferior a } 30 \% \text {, então é } \\
\text { apresentado novamente o conteúdo } \\
\text { reconfigurado para abranger as } \\
\text { dificuldades apresentadas pelos estudantes. } \\
\text { 4. Se o índice de acertos da turma for igual ou } \\
\text { maior que } 70 \% \text { do total de estudantes, então o } \\
\text { professor segue para exposição do conceito } \\
\text { subsequente. } \\
\text { 5. Se o índice de acertos da turma estiver } \\
\text { compreendido entre } 30 \% \text { e } 70 \% \text { do total de } \\
\text { estudantes, então aplica-se o método de } \\
\text { instrução por pares. }\end{array}$ \\
\hline $\begin{array}{l}\text { Ensino sob } \\
\text { Medida }\end{array}$ & $\begin{array}{l}\text { Aula Personalizada } \\
\text { (SANTOS, 2016) }\end{array}$ & $\begin{array}{l}\text { 1. Tarefas de leitura são disponibilizadas para os } \\
\text { estudantes antes de cada aula. } \\
\text { 2. No início de cada aula é feito um teste de } \\
\text { leitura a fim de identificar os conceitos que } \\
\text { foram bem compreendidos e os conceitos que } \\
\text { não foram compreendidos. } \\
\text { 3. O professor organiza as aulas a partir das } \\
\text { dificuldades apresentadas nos testes de leitura. }\end{array}$ \\
\hline
\end{tabular}


Nesse artigo foi realizada uma modificação na metodologia Ensino sob Medida. As questões de sondagem não foram enviadas para os estudantes, mas sim aplicadas no início de cada aula em forma de testes de leitura. As dificuldades identificadas através dos testes são analisadas e abordadas em aulas subsequentes e/ou através da sugestão de exercícios. Portanto, os testes de leitura cumprem com o papel desempenhado pelas questões de sondagem.

A Instrução por Pares e o Ensino sob Medida possuem em comum tarefas de leitura e testes de leitura. De fato, é possível encontrar na literatura trabalhos que utilizam as duas metodologias de forma integrada (ARAÚJO; MAZUR, 2013).

É importante ter em mente que a simples aplicação do teste de leitura não significa o uso do Ensino sob Medida, assim como a simples aplicação de testes conceituais não significa o uso da Instrução por Pares. Os testes de leitura servem para orientar a elaboração das aulas com atividades adaptadas à realidade de cada turma, enquanto os testes conceituais devem promover socialização do conhecimento à maneira da Instrução por Pares (SANTOS, 2016, p. 24-25).

Para maior eficiência no emprego das metodologias é interessante que o docente disponha de recursos que permitam avaliação imediata dos testes de leitura e dos testes conceituais. Uma sugestão relevante e muito interessante é o aplicativo Plickers (ARAUJO; JESUS; OLIVEIRA, 2017, p. 4-5). Este aplicativo permite criar testes e exibi-los através de projeção para todos os estudantes. O Plickers permite, ainda, a criação de cartões de respostas para cada estudante e, assim respostas podem ser escaneadas através de um smartphone.

\section{A sequência didática}

Nesse artigo são apresentados e discutidos: uma atividade POE sobre densidade (disponibilizada no apêndice A); quatro testes de leitura (TL) (disponibilizados no apêndice B); quatro questões conceituais que compõem uma atividade de Instrução por Pares (InP) (disponibilizadas no apêndice C).

Todas as tarefas de leitura, enviadas para os alunos, definem uma grandeza física, discutem as unidades de medida vinculadas a essa grandeza, discutem como realizar medidas dessa grandeza e iniciam com um texto sobre aplicação do conceito-chave no cotidiano ou em outra área do conhecimento. Elas abordam os conceitos de densidade, pressão, princípio de Stevin e empuxo.

Para aplicação integral da sequência é necessário dispor de 10 aulas, que totalizam 15 tempos de 45 minutos. Esse tempo é suficiente para aplicar todas as atividades criadas de acordo com a Tabela 2. A sequência foi aplicada em duas turmas de ensino médio, conforme especificado na introdução. 
Tabela 2 - Distribuição dos temas propostos por aula.

\begin{tabular}{|c|c|c|}
\hline Aula & Conceitos Abordados & Atividades Executadas \\
\hline Aula 1 - 1 tempo & Densidade & Aplicação do TL1 \\
\hline Aula 2-2 tempos & Densidade & Aplicação do POE \\
\hline Aula 3- 1 tempo & Densidade & Lab 1: Análise de teor alcóolico \\
\hline Aula 4- 2 tempos & Pressão & TL2, história do barômetro e exercícios \\
\hline Aula 5 - 1 tempo & Princípio de Stevin & TL3 \\
\hline Aula 6- 2 tempos & Princípio de Stevin & Exercícios e aplicações \\
\hline Aula 7 - 1 tempo & $\begin{array}{l}\text { Princípio de Stevin e } \\
\text { Vasos Comunicantes }\end{array}$ & InP e Experimentos Demonstrativos \\
\hline Aula 8 - 2 tempos & Empuxo & $\begin{array}{l}\text { TL } 4 \text { e Lab 2: determinação } \\
\text { do empuxo experimentalmente }\end{array}$ \\
\hline Aula 9-1 tempo & Empuxo & Exemplos \\
\hline Aula $10-2$ tempos & Empuxo & Exemplos \\
\hline
\end{tabular}

A Base Nacional Comum Curricular (BNCC) apresenta três competências específicas para Ciências da Natureza e suas Tecnologias para o Ensino Médio e cada uma dessas competências possui um conjunto de habilidades que devem ser alcançadas.

Contudo, a Base amarra determinadas habilidades a um conteúdo curricular específico. Entendemos que o conceito de habilidade é mais amplo e, por isso, uma mesma habilidade pode e deve ser desenvolvida através de conteúdos diversos.

Apesar disso, é possível enquadrar as aulas da sequência didática dentro da competência três. Diz a Base que é finalidade desta competência:

Investigar situações-problema e avaliar aplicações do conhecimento científico e tecnológico e suas aplicações no mundo, utilizando procedimentos e linguagens próprios das Ciências da Natureza, para propor soluções que considerem demandas locais, regionais elou globais, e comunicar suas descobertas e conclusões a públicos variados, em diversos contextos e por meio de diferentes mídias $e$ tecnologias digitais de informação e comunicação (BNCC, p. 560).

Esta competência apresenta nove habilidades. Ao invés de enumerá-las, destaca-se os conceitos-chave que integram a descrição de cada uma das nove habilidades: investigação; elaboração de hipóteses; emprego de instrumentos de medição; interpretação de texto, gráficos, tabelas, símbolos e códigos; realização de aplicações em contexto local e cotidiano.

A partir desse momento é feita uma breve apresentação de cada aula da sequência com destaque para habilidades desenvolvidas.

Aula 1: são realizados testes de leitura que tem por objetivo relacionar e interpretar as grandezas físicas envolvidas na tarefa de leitura correspondente. 
Aula 2: aplicação do POE sobre densidade. Esta atividade permite relacionar grandezas físicas; realizar proposições para explicações de fenômenos físicos; contextualizar os conhecimentos da física com o cotidiano e outras áreas da ciência.

Aula 3: é feito um experimento para determinar o teor alcóolico de uma cachaça com um densímetro, graduado em $\mathrm{g} / \mathrm{cm}^{3}$, e posteriormente com um alcoômetro, graduado em $\% \mathrm{v} / \mathrm{v}$. Por isso, é apresentada uma tabela que relaciona estas duas unidades. Portanto, são apresentados instrumentos de medidas, são trabalhadas habilidades para coleta e análise de dados e conceitos físicos são aplicados na área da indústria de alimentos.

A região de localização da escola possui alambiques, tem vocação para a área de alimentos e o público alvo pertence a cursos técnicos em Química e em Alimentos. Esses aspectos fundamentam a escolha por uma atividade experimental que tem interface com a Indústria de Alimentos. Nesse sentido, é interessante que o professor leve em consideração o público-alvo ao realizar as escolhas dos experimentos.

Aula 4: são realizados testes de leitura e é apresentada a história do barômetro de mercúrio com sua importância na meteorologia.

Aula 5: idem a aula 1.

Aula 6: nessa aula é realizada uma atividade em que o aluno precisa buscar no site do Instituto Nacional de Meteorologia (INMET) as pressões atmosféricas para distintas cidades a fim de correlacionar a pressão atmosférica com a altitude. Portanto, são trabalhadas habilidades de interpretação de diferentes linguagens e símbolos.

Aula 7: foi aplicada uma atividade baseada na metodologia Instrução por Pares tal como sugerida por Mazur (2015). Nessa aula foi feita uma discussão sobre vasos comunicantes e logo em seguida foram aplicadas quatro questões conceituais: três sobre vasos comunicantes e uma sobre densidade. A questão sobre densidade foi colocada para testar se os alunos ainda acertariam uma questão conceitual de um tema que foi abordado anteriormente.

Aula 8: são realizados dois experimentos que estão explicados na tarefa de leitura do aluno e têm por finalidade investigar o significado físico do empuxo.

Aulas 9 e 10: são propostos exercícios gerais sobre hidrostática com ênfase no conceito de empuxo e suas aplicações. Essas aulas são elaboradas a fim de trabalhar interpretação de fenômenos físicos através da linguagem matemática com uso de equações.

\section{Resultados}

Os resultados estão divididos em duas partes, quantitativos e qualitativos. Uma análise dos índices de acertos dos testes é feita baseada nos relatórios gerados pelo Plickers. 
Ademais, são analisadas concepções alinhadas às respostas apontadas pelos estudantes para cada questão do teste conceitual e da atividade POE.

\section{IV.1. Resultados Quantitativos}

\section{IV.1.1 Testes de Leitura}

A Tabela 3 apresenta o índice de acertos das turmas para cada um dos quatro testes de leitura e a Figura 1 exibe a nota média para cada uma das vinte e sete questões que integram os quatro testes de leitura.

Tabela 3 - Índice de acerto em cada teste de leitura por turma.

\begin{tabular}{ccc}
\hline $\begin{array}{c}\text { Teste de } \\
\text { Leitura }\end{array}$ & $\begin{array}{c}\mathbf{2}^{\mathbf{o}} \text { ano } \\
\text { Turma 1 }\end{array}$ & $\begin{array}{c}\mathbf{2}^{\mathbf{0}} \text { ano } \\
\text { Turma 2 }\end{array}$ \\
\hline TL1 & $79 \%$ & $91 \%$ \\
\hline TL2 & $90 \%$ & $83 \%$ \\
\hline TL3 & $80 \%$ & $68 \%$ \\
\hline TL4 & - & $88 \%$ \\
\hline
\end{tabular}

A Turma 1 não teve o resultado do TL4 computado porque a internet estava indisponível no dia de aplicação do teste. A média do índice de acerto e o respectivo desviopadrão para a Turma 1 é 85 (17) \%, enquanto para a Turma 2 é 82 (21) \%.

As altas médias para os testes de leitura refletem um bom nível de comprometimento com as tarefas por parte dos estudantes. Além disso, corroboram também para a ideia de que as tarefas de leitura permitem introduzir conceitos e informações relevantes para o desenvolvimento dos temas antes do acontecimento das aulas.

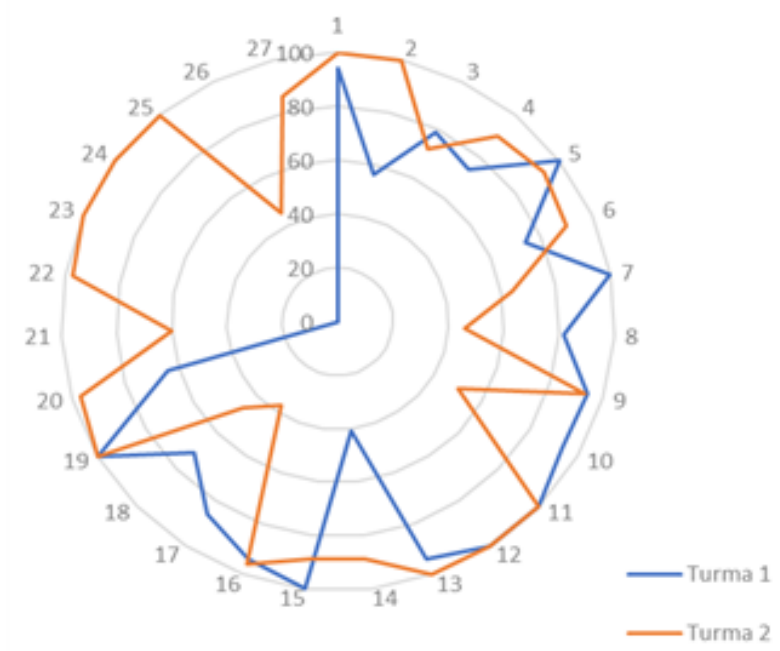

Fig. 1 -Índice percentual médio de acertos por questão para cada turma. 
Por outro lado, os desvios-padrões são altos. O motivo pelo qual isso ocorre é que eles são sensíveis à amplitude dos dados.

Por exemplo, a questão 1 (TL1) alcançou bons índices em ambas as turmas (94\% e $100 \%$ ). Ela é considerada fácil, pois averigua diretamente se o estudante leu o material e incorporou mentalmente a definição matemática para o conceito densidade. Por outro lado, a questão 14 (TL2) alcançou índice igual a 41\% na Turma 1 e índice igual a 89\% na Turma 2. Ela é considerada de nível médio por exigir interpretação e compreensão da relação entre altitude e pressão.

A amplitude dos índices percentuais está compreendida entre $41 \%$ e $100 \%$ na Turma 1, enquanto na Turma 2 estes índices variam entre $45 \%$ e $100 \%$.

A Fig. 2 exibe as distribuições das questões por faixa de nota, por turma. Sendo assim, 65\% do número de questões possuem média de acertos entre $80 \%$ e $100 \%$ para a Turma 1 , enquanto $78 \%$ das questões possuem média compreendida nesse mesmo intervalo para a Turma 2 .

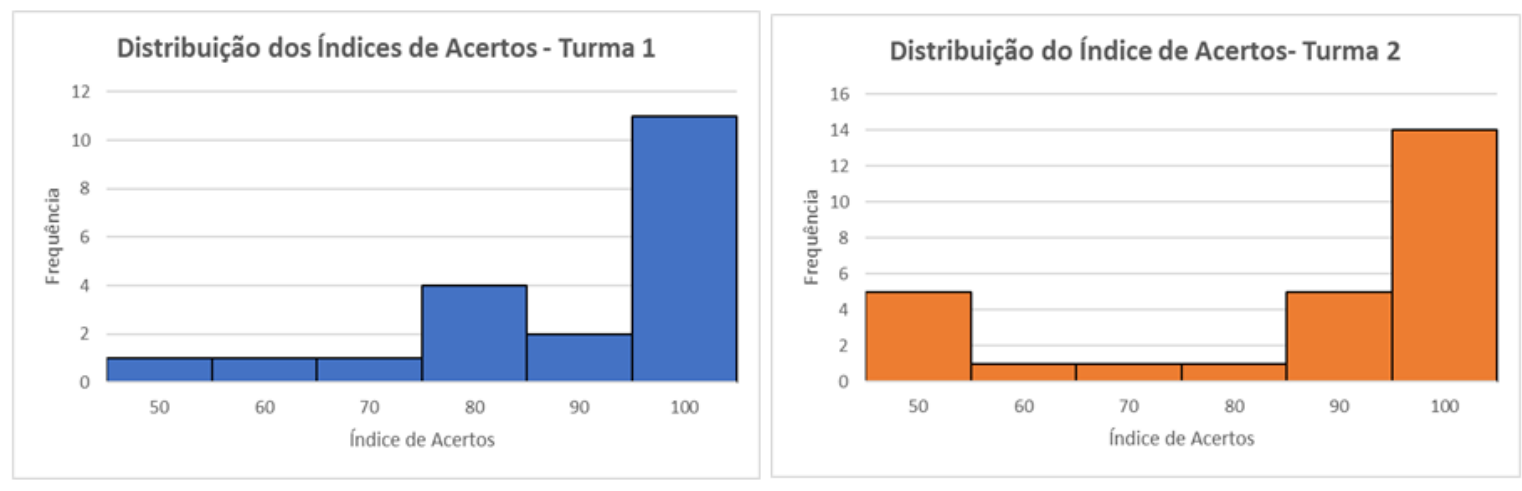

Fig. 2 - Distribuição de questões por faixa de notas.

\section{IV.1.2 Instrução por Pares}

Quatro questões conceituais foram aplicadas nas duas turmas de acordo com as regras estabelecidas pela metodologia Instrução por Pares. A metodologia é normalmente aplicada quando o índice inicial de acertos está compreendido entre $30 \%$ e $70 \%$, porém não há impedimento para que a discussão entre pares ocorra quando o índice de acertos estiver fora desse intervalo.

As Tabelas 4 e 5 mostram o índice de acertos após a primeira votação e após a segunda votação. A segunda votação ocorre após os alunos discutirem entre si a questão conceitual. É esperado que após a segunda votação haja aumento no índice de acertos da turma. 
Tabela 4 - Índice de acertos para cada questão para a Turma 1.

\begin{tabular}{ccc}
\hline Questão Conceitual & $\begin{array}{c}\text { Índice de Acertos (\%) } \\
\mathbf{1}^{\mathbf{0}} \text { votação }\end{array}$ & $\begin{array}{c}\text { Índice de Acertos (\%) } \\
\mathbf{2}^{\mathbf{0}} \text { votação }\end{array}$ \\
\hline $\mathbf{1}$ & 85 & - \\
\hline $\mathbf{2}$ & 15 & 23 \\
\hline $\mathbf{3}$ & 14 & 33 \\
\hline- & 73 & \\
\hline
\end{tabular}

Tabela 5 - Índice de acertos para cada questão para a Turma 2.

\begin{tabular}{ccc}
\hline Questão Conceitual & $\begin{array}{c}\text { Índice de Acertos (\%) } \\
\mathbf{1}^{\mathbf{0}} \text { votação }\end{array}$ & $\begin{array}{c}\text { Índice de Acertos (\%) } \\
\mathbf{2}^{\mathbf{0}} \text { votação }\end{array}$ \\
\hline $\mathbf{1}$ & 74 & - \\
\hline $\mathbf{2}$ & 11 & 15 \\
\hline $\mathbf{3}$ & 70 & - \\
\hline $\mathbf{4}$ & 19 & 19 \\
\hline
\end{tabular}

Os estudantes da Turma 1 alcançaram índice superior a 70\% nas questões 1 e 4 e inferior a 30\% nas questões 2 e 3 . Os estudantes da Turma 2 alcançaram índice superior a 70 $\%$ nas questões 1 e 3 e inferior a $30 \%$ nas questões 2 e 4 . Contudo, os estudantes discutiram todas as questões com índice inferior a 30\%.

Após as discussões das questões, a Turma 1 elevou o índice da questão 2 de $15 \%$ para $23 \%$ e o índice da questão 3 de $14 \%$ para $33 \%$. A Turma 2 elevou o índice da questão 2 de $11 \%$ para $15 \%$ e manteve inalterado o índice da questão 4 .

A alteração nos índices de acertos decorrente das discussões promovidas entre os estudantes pode ser quantificada através do ganho de Hake (ARAÚJO et. al, 2017, p.5). O ganho de Hake consiste na razão entre a diferença do índice de acertos obtidos nas duas votações e o ganho máximo que é permitido alcançar após a segunda votação, sendo normalizada de 0 a 1 .

Um ganho de Hake mais próximo de 0 (zero) significa que o mínimo de respostas sofreu alteração para a resposta correta, após as discussões realizadas. Um ganho mais próximo de 1 significa que o máximo de respostas foram alteradas para a resposta correta, após a segunda votação. Portanto, o índice de 19\% na questão 4 indica que os estudantes da Turma 2 mantiveram suas respostas após as discussões entre eles. A Tabela 6 exibe o ganho de Hake para as questões 2 e 3 na Turma 1 e para as questões 2 e 4 na Turma 2. 
Tabela 6 - Ganho de Hake por Turma.

\begin{tabular}{ccc}
\hline Questão Conceitual & Ganho de Hake - Turma 1 & Ganho de Hake - Turma 2 \\
\hline $\mathbf{2}$ & 0,09 & 0,04 \\
\hline $\mathbf{3}$ & 0,22 & - \\
\hline
\end{tabular}

\section{IV.2 Resultados qualitativos}

\section{IV.2.1 Instrução por Pares}

A partir desse momento são feitas algumas discussões para justificar o motivo pelo qual ocorreram índices inferiores a 30\% nas questões 2, 3 e 4 em pelo menos uma das turmas, conforme mostram as Tabelas 4 e 5 .

A questão 2 promove uma discussão sobre a altura adequada da saída em um bule de café em relação a "boca" do bule. O modelo 1 possui saída superior a entrada; o modelo 2 possui saída no mesmo nível da entrada; o modelo 3 possui saída inferior a entrada. A maioria dos alunos acreditam que não existe diferença prática entre os modelos 1 e 2 . Somente dois alunos, considerando as duas turmas, consideram que o modelo 3 de bule é apropriado. Isso mostra que eles entenderam que a saída não pode ser mais baixa do que a entrada pois do contrário haveria transbordamento do líquido. Contudo, tiveram dificuldade na compreensão da razão pela qual não é adequado ter uma saída mais alta do que a boca.

A questão 3 tem por objetivo fazer com que o aluno compare qualitativamente a pressão total sobre pontos distintos. Dentre as concepções observadas estão aquelas que consideram as pressões nos pontos $a$ e $d$ iguais. Ficou evidente, durante as discussões, que esses alunos acreditam nessa opção pelo fato de acima desses pontos existir somente ar e desconsiderem que os pontos estão em níveis diferentes.

Ainda sobre a questão 3, somente quatro alunos na Turma 1 e cinco alunos na Turma 2 marcaram as respostas $b$ ou $c$. Não foi evidenciado nenhum raciocínio que justificasse a opção por essas respostas, fato que leva a conclusão de que esses alunos ou "chutaram" a resposta ou houve confusão na escolha das respostas.

Finalmente, é notória a discrepância para a questão 4 entre os índices atingidos por cada turma. A Turma 1 atingiu um índice superior a 70\%, enquanto a Turma 2 atingiu índice inferior a 30\%. Porém, as opções por respostas erradas estão motivadas ou na consideração das situações dois e três como idênticas ou na inversão do raciocínio sobre a relação da densidade do objeto com a densidade do fluido. Essa inversão levaram os alunos à opção pela resposta do item $b$ ao invés da resposta certa no item $d$.

\section{IV.2.2 POE}

A proposta do POE é desenvolver um conceito através de atividades experimentais que suscitem o conhecimento prévio do estudante e promovam conflito cognitivo. 
Os cinco experimentos escolhidos possuem a mesma finalidade de desenvolver a percepção de que para um objeto afundar ou flutuar é necessário relacionar a densidade do objeto com a densidade do fluido no qual está imerso o objeto.

Os experimentos 1, 2 e 3 são construídos para evidenciar o fato de que a grandeza relevante é a relação entre massa e volume, a densidade. A maioria dos estudantes conhece a definição matemática sobre densidade e são capazes de prever corretamente que os cubos de borracha e madeira flutuam quando imersos em água, enquanto os dados de plástico afundam. Portanto, as três primeiras questões não provocaram conflito cognitivo. Porém, foram importantes para a construção do debate profícuo entre os estudantes.

O experimento 4 é análogo aos anteriores que utilizava cubos, porém é perceptível que os estudantes associem que frutas maiores afundam e frutas menores flutuam. Portanto, para esse experimento existe conflito cognitivo. É notório que nenhum estudante tenha sugerido calcular a densidade das frutas de alguma forma e comparar com a densidade da água.

O experimento 5 também provoca conflito cognitivo. A grande maioria dos estudantes realiza a previsão de que ambas as latas afundarão igual. Eles percebem que as latas de refrigerante possuem o mesmo volume, porém não atentam para o fato de que elas possuem massas distintas entre si.

Os experimentos 4 e 5 revelam que os estudantes acreditam, intuitivamente, que afundar ou flutuar depende somente dos volumes, no caso das frutas e das latas de refrigerante. Isto ocorre, apesar de muitos deles conhecerem a definição matemática do conceito densidade e realizarem as previsões corretas para os experimentos 1,2 e 3 .

$\mathrm{O}$ sucesso da atividade é verificado quando as respostas relativas às questões 8 e 9 são analisadas. A grande maioria dos estudantes acertam essas questões e conseguem visualizar que o experimento 9 (do Mar Morto) é um exemplo na natureza do experimento 8 (do ovo).

Fica evidente que uma atividade POE é capaz de gerar bastante interação e comprometimento entre os estudantes por si mesma. É comum perceber que estudantes pouco participativos em aulas expositivas passem a expressar suas curiosidades em aulas que são norteadas pelo POE.

\section{Considerações finais}

A proposta desse trabalho é estruturar uma sequência didática baseada em concepções que norteiam as metodologias de aprendizagem ativa. Foram escolhidas três metodologias dentre mais de vinte disponíveis na literatura (LOVATO et al., 2018; HENDERSON; DANCY; BUGAJ, 2012): o POE; a Instrução por Pares; o ensino sob medida. 
Nenhuma dessas metodologias sozinhas é capaz de resolver todos os problemas estruturais do ensino de Ciências. Contudo, constituem excelentes alternativas para dinamizálo ao incluir o aluno como protagonista do processo de aprendizagem.

Atividades dessa natureza permitem diagnosticar, compreender e discutir concepções alternativas, entender a relação dos estudantes com a disciplina, com os seus pares e com o material didático. Tudo isso ocorre pelo fato dessas atividades propiciarem espaços e recursos para manifestações de ideias originais dos estudantes.

Em suma, as metodologias são pensadas para promoção da aprendizagem, porém elas também servem de ferramentas para o professor compreender questões humanas e sociais presentes na sala de aula que, usualmente, ficam veladas em uma aula com a "metodologia quadro e giz". Na verdade, o processo de aprendizagem acontece mais naturalmente quando o professor considera todas essas relações e conscientiza-se de ferramentas que permitem interferir nessa realidade.

O POE, em específico, é uma excelente ferramenta para construir atividades de natureza experimental-investigativa mesmo em situações em que o professor não possui boa infraestrutura de laboratório e recursos financeiros para aquisição de modernos equipamentos didáticos (HAYSOM, 2010; LIEW, 2009, SANTOS, 2015; SASAKI, 2017). É possível transformar o próprio espaço da sala de aula em um espaço para o qual aconteçam atividades dessa natureza quando aplicativos de celulares e simuladores de internet são considerados (BALEN, 2005; TAO, 1999; KEARNEY, 2001).

A Instrução por Pares, por sua vez, constitui uma excelente ferramenta para promover interação social e discussões qualitativas sobre os conceitos entre os estudantes. Essa interação foi observada, positivamente, ao longo de aplicação dos testes de leitura e das questões conceituais.

O Ensino sob Medida através de seus testes de leitura permite construir as aulas baseadas em dificuldades reveladas pelos estudantes. É uma metodologia bastante eficaz quando integrada a Instrução por Pares e ao POE.

Dessa forma, a sequência didática proposta ressalta a ideia de que é possível criar aulas mais interessantes, capazes de desenvolver habilidades individuais e coletivas, abstratas e concretas através da integração de diferentes metodologias.

Não foram aplicados instrumentos de avaliação formais (provas e testes) para os estudantes após a aplicação da sequência didática, sobretudo devido ao tempo de isolamento social que está sendo vivido neste ano. Contudo, é possível realizar considerações positivas sobre a aplicação da sequência didática quando avaliação é entendida como um processo contínuo e não pontual. Nesse sentido, foram realizadas avaliações quantitativas e qualitativas em todo o processo de aplicação da sequência.

Avaliações quantitativas são aquelas relacionadas aos testes de leitura e as questões conceituais discutidas ao longo do trabalho. Os estudantes de cada turma obtiveram médias de $85 \%$ e $82 \%$ referentes aos testes de leitura. Essas médias são altas, revelam o 
comprometimento dos estudantes com as atividades e permitem ao professor avaliar quais questões presentes nos testes de leitura devem ser mais aprofundadas em cada turma. Essa seleção de como caminhar com cada turma fundamenta o Ensino sob Medida utilizado para nortear a construção das aulas.

Além disso, existem os resultados quantitativos associados as questões conceituais para as quais foram empregados o método de Instrução por Pares. Cada uma dessas questões foi aplicada novamente quando o índice percentual de acertos era menor do que $70 \%$ e para essas questões foi calculado o ganho de Hake. O ganho variou entre 0 (zero) e 0,22 nas duas turmas. Isso mostra que a interação social e a discussão dos conceitos propiciam a compreensão dos conceitos discutidos nas situações propostas por um maior número de estudantes quando ocorre a interação entre eles.

Por fim, duas falas foram constantes durante a aplicação da sequência didática: "com esse método estamos aprendendo mais" ou "estamos entendendo pra que serve a Física". Essas falas mostram que os estudantes percebem através dos métodos que a Física não é somente um amontoado de fórmulas e que possui um papel relevante para explicar situações observadas no cotidiano.

\section{Referências bibliográficas}

ALVARADO, M. S. A.; MORA, C.; REYES, C. B. C. Peer Instruction to adress alternative conceptions in Einstein's special relativity. Revista Brasileira de Ensino de Física, v. 41, n. 4, p. 1-14, 2019.

ARAÚJO, A.V. R. et al. Uma associação do método Peer Instruction com circuitos elétricos em contextos de aprendizagem ativa. Revista Brasileira de Ensino de Física, v. 39, n. 2, p. $1-6,2017$.

ARAÚJO, I. S.; MAZUR, E. Instrução pelos colegas e ensino sob medida: uma proposta para o engajamento dos alunos no processo de ensino aprendizagem de Física. Caderno Brasileiro de Ensino de Física, v. 30, n. 2, p. 362-384, 2013.

BALEN, O.; NETZ, P. A. Aplicação da modelagem e simulação no ensino de modelos de sistemas gasosos. Acta Scientiae, v. 7, n. 2, p. 29-39, 2005.

BASE NACIONAL COMUM CURRICULAR. Disponível em:

$<$ http://basenacionalcomum.mec.gov.br/images/BNCC_EI_EF_110518_versaofinal_site.pdf> . Acesso em: 29 jun. 2020.

BORGES, A. T. Novos Rumos para o Laboratório Escolar de Ciências. Caderno Brasileiro de Ensino de Física, v. 19, n. 3, p. 291-313, 2002. 
CACHAPUZ, A; PRAIA, J; JORGE, M. Da educação em ciência às orientações para o ensino das ciências: um repensar epistemológico. Ciência \& Educação, v. 10, n. 3, p. 363-381, 2004.

CHIQUETTO, M; KRAPAS, S. Livros didáticos baseados em apostilas: como surgiram e por que foram amplamente adotados. Revista Brasileira de Pesquisa em Educação em Ciências, v. 12, n. 3, p. 173-191, 2012.

CID, A. S; CORREA, T. Venturino: análise da variação de pressão em um tubo de Venturi utilizando o Arduino e sensor de pressão. Revista Brasileira de Ensino de Física, v. 41, n. 3, p. 1-7, 2019.

CUPITA, L. A. L. Just in time teaching: a strategy to encourage student's engagement. HOW, v. 23, n. 2, p. 89-105, 2016.

DEMERCI, C. Constructing a philosophy: prospective teacher's opinions about constructivism. Procedia Social and Behavorial Sciences, v. 9, p. 278-285, 2010.

De PAUlA, J; FIGUEIREDO, N; FERRAZ, D. P. A. Peer Instruction e Vygotsky: uma aproximação a partir de uma disciplina de astronomia no ensino superior. Caderno Brasileiro de Ensino de Física, v. 37, n. 1, p. 127-145, 2020.

HAYSOM, J.; BOWEN, M. Predict, Observe, Explain: Activities Enhancing Scientific Understanding. Arlington: NSTA Press, 2010.

LIEW, C. W. Effectiveness of Predict-Observe-Explain Technique. Düsseldorf: Lambert Academic Publishing, 2009.

HENDERSON, C; DANCY, M; BUGAJ, M. Use of research-based instructional strategies in introductory physics: Where do faculty leave the innovation-decision process? Physical Review Physics Education Research, v. 8, n. 2, p. 1-15, 2012.

INSTITUTO NACIONAL DE METEOROLOGIA. Disponível em:

$<$ http://www.inmet.gov.br/portal/index.php?r=estacoes/estacoesautomaticas>. Acesso em: 13 abr. 2020.

KIBIRIGE, I; OSODO, J; TLALA, K. The effect of predict-explain-strategy on learners misconceptions about dissolved salts. Mediterranean Journal of Social Sciences, v. 5, n. 4, p. 300-310, 2014. 
KIELT, E. D.; da SILVA, S. C. R.; MIQUELIN, A. F. Implementação de um aplicativo para smarphones como sistema de votação em aulas de Física com PEER INSTRUCTION. Revista Brasileira de Ensino de Física, v. 39, n. 4, p. 1-8, 2017.

LEAL, E. L. C. et al. Implementation of Just in Time Teaching metohodology in mathematics and natural sciences study in high school instituitions of Colombia northeast. Journal of Physics: Conference Series. $1161012016,2019$.

LOVATO, F; MiCHELOTTI, A.; da SILVA , C.; LORETTO, E. Metodologias ativas de aprendizagem: uma breve revisão. Acta Scientiae , v. 20, n. 2, p. 154-171, 2018.

MAZUR, E. Peer Instruction: a revolução da aprendizagem ativa. Porto Alegre, 2015.

MÜLlER, M. et al. Uma revisão da literatura acerca da implementação da metodologia interativa de ensino PEER INSTRUCTION (1991 A 2015). Revista Brasileira de Ensino de Física, v. 39, n. 3, p. 1-20, 2017.

SANTOS, R. J.; SASAKI, D. G. G. Uma metodologia de aprendizagem ativa para o ensino de mecânica em educação de jovens e adultos. Revista Brasileira de Ensino de Física, v. 37, n. 3, p. 1-9, 2015.

SASAKI, D. G. G.; JESUS, V. L. B. Avaliação de uma metodologia de aprendizagem ativa em óptica geométrica através da investigação das reações dos alunos. Revista Brasileira de Ensino de Física, v. 39, n. 2, p. 1-10, 2017.

SANTOS, M. B. Uma sequência didática com os métodos instrução por colegas (Peer Instruction) e ensino sob medida (Just-in-time teaching) para o estudo de ondulatória no ensino médio. 2016. Dissertação (Mestrado em Ensino de Física) - Instituto de Física, Universidade Federal do Rio Grande do Sul, Porto Alegre.

TAO, P. K.; GUNSTONE, R. F. A process of conceptual change in force and motion during computer-supported Physics instruction. Journal of Research in Science Teaching, v. 36, p. 859-882, 1999.

WHITE, R.; GUNSTONE, R. Probing understanding. New York: Routledge, 1992.

\section{Apêndices}

Nos apêndices estão disponibilizados materiais que integram a sequência didática de hidrostática. Estão disponíveis: o POE (apêndice A); os testes de leitura (apêndice B); as 
questões conceituais da Instrução por Pares (apêndice C). As tarefas de leitura não estão disponíveis por entendermos que não são essenciais para a realização das discussões presentes ao longo do artigo.

\section{Apêndice A: O POE da Sequência Didática}

Esta seção apresenta o POE sobre densidade. O POE permite trabalhar habilidades de comunicação oral e escrita; familiarização com símbolos, unidades e grandezas de medida; familiarizar-se com instrumentos de medidas; socialização do conhecimento quando as discussões acontecem em grupos.

\section{a) Previsão/Motivação}

1. Imagine que um cubo de 6 gramas é jogado dentro de um reservatório de água. Somente com essa informação, é possível saber se o cubo afunda ou flutua? Sim ou não? Por quê?

2. Imagine que você jogue no reservatório dois cubos de $2 \mathrm{~g}$, mas um possui volume maior do que o outro. Qual deles afundará mais? Por quê?

3. Imagine, agora, que dois cubos possuem volumes iguais de $64 \mathrm{~cm}^{3}$, mas um tem massa igual a $6 \mathrm{~g}$ e o outro massa igual a $15 \mathrm{~g}$. Qual deles afundará mais? Por quê?

4. Imagine que os seguintes objetos são mergulhados em um reservatório com água. Marque F se ele flutua e A se ele afunda.
( ) Tomate
( ) Limão
( ) Maçã
( ) Batata
( ) Cenoura
( ) Ovo
( ) Uva
( ) Laranja

5. Você mergulha uma lata de Coca-Cola zero e outra lata original em água. Qual delas deve afundar mais e por quê?

\section{b) Observação}

Essa etapa está constituída por três experimentos:

Experimento 1: Meça a massa e o volume para cada cubo fornecido pelo professor e verifique se o mesmo afunda ou flutua.

\begin{tabular}{|l|l|l|l|}
\hline & Massa $(\mathbf{g})$ & Volume $\left(\mathbf{c m}^{\mathbf{3}}\right)$ & Afunda ou Flutua? \\
\hline Dado 1 - Plástico & & & \\
\hline Dado 2 - Borracha & & & \\
\hline Dado 3 - Madeira menor & & \\
\hline Dado 4 - Madeira maior & & \\
\hline
\end{tabular}


Experimento 2: Sobre a mesa estão alguns alimentos. Marque A para aqueles que afundam e $\mathrm{F}$ para aqueles que flutuam.
( ) Tomate
( ) Limão
( ) Maça
( ) Batata
( ) Cenoura
( ) Ovo
) Uva
( ) Laranja

Experimento 3: Sobre a mesa também estão as latinhas de Coca- Cola. O que você observa quando as mergulha em água?

Experimento 4: Calcule a relação entre massa e volume e verifique se cada dado afunda ou flutua na água.

\begin{tabular}{|l|l|l|}
\hline & $\begin{array}{l}\text { Massa/Volume } \\
\left(\mathbf{g} / \mathbf{c m}^{\mathbf{3}}\right)\end{array}$ & Afunda ou Flutua? \\
\hline Dado 1 - Plástico & & \\
\hline Dado 2 - Borracha & & \\
\hline Dado 3 - Madeira menor & & \\
\hline Dado 4 - Madeira maior & & \\
\hline
\end{tabular}

Experimento 5: Sobre a mesa existe um equipamento chamado densímetro. Meça a densidade da água.

\section{c) Explicação}

6. A relação entre massa e volume é critério para saber se um corpo afunda ou flutua de acordo com o que você observou? Por quê?

7. Explique o motivo pelo qual uma lata de Coca-Cola afunda mais do que a outra. Você deve basear sua resposta em informações sobre as massas e volumes da lata.

8. Um ovo cozido ao ser mergulhado na água afunda, mas ele flutua após adicionar uma determinada quantidade de sal. Faça o experimento e explique-o.

9. A pessoa da foto abaixo está no Mar Morto. Qual é o motivo pelo qual a pessoa não afunda, mesmo sem o uso de boias.

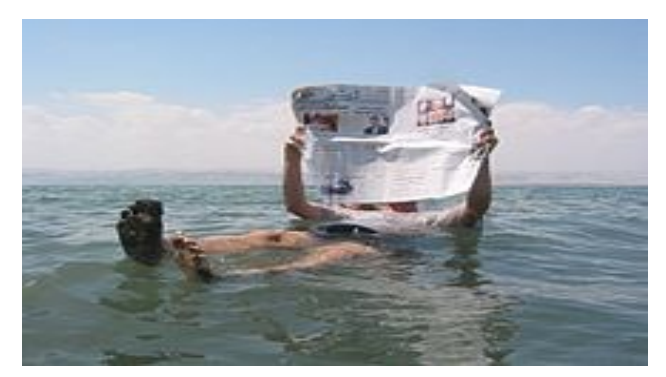

Fig. 3 - Disponivel em: <https://guia.melhoresdestinos.com.br/mar-morto-2286354-l.html>. Acesso em: 20 jun. 2020. 


\section{Apêndice B: Testes de Leitura}

A seguir serão apresentados cada uma das 27 questões presentes nos 4 testes de leitura com as opções de resposta e a indicação da resposta correta em vermelho.

Q1 (TL1). Qual é a expressão matemática para o cálculo de densidade?
a. $\quad \mathrm{m}=\mathrm{v} \cdot \mathrm{d}$
c. $d=m / v$
b. $\quad d=m \cdot v$
d. $v / m$

Q2 (TL1). Qual é unidade de densidade no Sistema Internacional de Medidas?
a. $\mathrm{g} / \mathrm{cm}^{3}$
c. $\mathrm{kg} / \mathrm{m}^{3}$
b. $\quad$ g.cm ${ }^{3}$
d. $\mathrm{kg} \cdot \mathrm{m}^{3}$

Q3 (TL1). O chumbo é menos denso do que o algodão.
a. Verdadeiro
b. Falso

Q4 (TL1). Qual conceito físico fundamenta o funcionamento do densímetro?
a. Pressão
c. Empuxo
b. Densidade
d. Energia

Q5 (TL1). Qual dos instrumentos abaixo serve para medir o teor alcóolico de uma cachaça?
a. Béquer
c. Barômetro
b. Dinamômetro
d. Densímetro

Q6 (TL1). Qual das unidades abaixo não serve para volume?
a. $\quad \mathrm{m}^{3}$ - metro cúbico
b. $\quad \mathrm{cm}^{3}$ - centímetro cúbico
c. 1 - litro
d. g-grama

Q7 (TL2). Qual é a definição matemática de pressão?
a. $\quad \mathrm{P}=\mathrm{F} . \mathrm{A}$
c. $P=F / A$
b. $\quad \mathrm{P}=\mathrm{m} . \mathrm{g}$
d. $F=P / A$

Q8 (TL2). Qual é a unidade de pressão no S.I.?
a. $\mathrm{mmHg}$
b. atm
b. bar
d. Pa

Q9 (TL2). Qual das unidades abaixo não é uma unidade de pressão?
a. $\mathrm{N} / \mathrm{m}^{2}$
c. atm
b. Bar
d. $\mathbf{N}$

Q10 (TL2). N $/ \mathrm{m}^{2}$ recebe o nome de...
a. Bar
b. Pascal
c. Atmosfera 
Q11 (TL2). Quanto vale $5 \mathrm{~N} / \mathrm{m}^{2}$ em Pascal?
a. $5 \mathrm{~Pa}$
c. $15 \mathrm{~Pa}$
b. $\quad 10 \mathrm{~Pa}$
d. $20 \mathrm{~Pa}$

Q12 (TL2). $76 \mathrm{cmHg}$ é igual a $1 \mathrm{~atm}$.
a. Verdadeiro
b. Falso

Q13 (TL2). Qual instrumento serve para medir pressão atmosférica?
a. Dinamômetro
c. Barômetro
b. Balanca
d. Biruta

Q14 (TL2). A pressão atmosférica no topo da Cordilheira dos Andes é maior do que em Valença?
a. Verdadeiro
b. Falso

Q15 (TL2). Quem inventou o barômetro?
a. Galileu Galilei
b. Evangelista Torricelli
c. Isaac Newton
d. Blaise Pascal

Q.16 (TL2). Quanto vale a pressão atmosférica no nível do mar em milímetro de mercúrio?
a. $\quad 840 \mathrm{mmHg}$
c. $900 \mathrm{mmHg}$
b. $\quad 700 \mathrm{mmHg}$
d. $760 \mathrm{mmHg}$

Q17 (TL3 - Turma 1). Imagine um peixe dentro do rio e um outro peixe idêntico ao primeiro dentro de um aquário. Os dois peixes estão a $50 \mathrm{~cm}$ de profundidade.
a. A pressão que atua sobre o peixe do rio é maior.
b. A pressão que atua sobre os dois peixes é igual.
c. A pressão que atua sobre o peixe do aquário é maior.
d. Impossível responder sem valores numéricos.

Q 18 (TL3 - Turma 1). Imagine que um mergulhador entre em um tanque de água doce e posteriormente entre no mar aberto. Nas duas situações atinge 10 metros de profundidade.
a. O mergulhador no tanque sofre pressão maior.
b. O mergulhador no mar sofre pressão maior.
c. Os dois sofrem a mesma pressão.
d. Impossível responder sem valores numéricos.

Q 19 (TL3 -Turma 1). Imagine que você mergulhe a 10 metros de profundidade em um rio de outro planeta que também tenha água e a aceleração da gravidade nesse planeta é duas vezes maior do que na Terra.

a. A pressão exercida sobre você é maior na Terra. 
b. A pressão é a mesma nos dois planetas.

c. A pressão exercida sobre você é maior no outro planeta.

d. Impossível responder sem dados numéricos.

Q 20 (TL3 - Turma 1). Todos os quatro vasos da figura estão preenchidos com água. $\mathrm{O}$ vaso 1 é o da esquerda e o vaso 4 é o da direita.

a. A pressão é maior no fundo do vaso 1.

b. A pressão é maior no fundo do vaso 2 .

c. A pressão é maior no fundo do vaso 3.

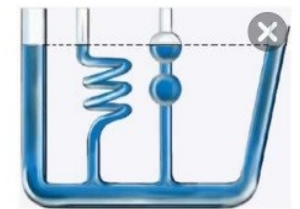

Fig. 4.

d. Nenhuma das respostas.

Q 21 (TL3 - Turma 2). A pressão no fundo da piscina depende...

a. da pressão feita pela coluna de água.

b. da pressão feita pela coluna de água mais a pressão atmosférica.

c. da pressão atmosférica

d. nenhuma das respostas acima.

Q 22 (TL3 -Turma 2). Qual expressão matemática você usaria para calcular a pressão no fundo de uma piscina?
a. $p=p_{\text {atm }}+$ d.g.h
b. $\quad p=p_{a t m}$
c. $\quad p=$ d.g.h

Q 23 (TL3-Turma 2). Qual é o nome do princípio que relaciona pressão com profundidade?
a. Princípio de Pascal
b. Princípio de Fermat
c. Princípio de Bernoulli
d. Princípio de Stevin

Q 24 (TL3-Turma 2). O princípio de Stevin é adequado para calcular pressão em fluidos compressíveis?
e. Verdadeiro
b. Falso

Q 25(TL4). Qual é a unidade de empuxo?
a. $\quad \mathrm{N} / \mathrm{m}^{2}$
c. $\mathrm{Kg} / \mathrm{m}^{3}$
f. $\mathbf{N}$
d. Pascal

Q 26 (TL4). Empuxo é uma força que sempre aponta para baixo?
g. Verdadeiro
b. Falso

Q 27 (TL4). Qual é o nome do princípio que define o conceito de empuxo?
a. Princípio de Stevin 

b. Princípio de Arquimedes
c. Princípio de Pascal
d. Princípio de Torricelli

Q.28 (TL4). Empuxo é igual ao peso do volume do objeto.
a. Verdadeiro
b. Falso

Q 29 (TL4). O peso aparente é sempre menor do que o peso do objeto.
a. Verdadeiro
b. Falso

Q. 30 (TL4). O peso de um objeto é $5 \mathrm{~N}$ e o seu peso aparente é igual a $3 \mathrm{~N}$. Quanto vale o empuxo?
a. $\quad 1 \mathrm{~N}$
c. $8 \mathrm{~N}$
b. $\quad 2 \mathrm{~N}$
d. $15 \mathrm{~N}$

Q 31 (TL4). Considere que $100 \mathrm{ml}$ de água transbordam ao mergulhar um objeto em uma proveta cheia até sua boca. Quanto vale a força de empuxo nesse caso?
a. $1 \mathrm{~N}$
c. $100 \mathrm{~N}$
b. $\quad 10 \mathrm{~N}$
d. $1000 \mathrm{~N}$

\section{Apêndice C: Questões da Instrução por Pares}

A seguir serão apresentadas cada uma das questões conceituais com as opções de resposta e a indicação da resposta correta em vermelho. As Fig. 5, 6, 7 e 8 são retiradas de um livro do ensino médio .

1. (UFRGS) A Fig. 5 representa quatro recipientes cheios de água e abertos na parte superior. Em qual deles a pressão que a água exerce sobre a base é maior?
a. 1
b. 2
c. 3
d. 4

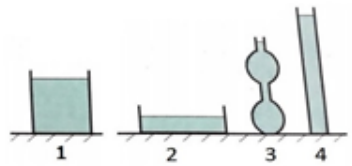

Fig. 5.

2. (Cesgranrio - RJ) Se você fosse consultor técnico de uma fábrica de bules, quais modelos seguintes você recomendaria fabricar, para que o produto funcione corretamente de tal forma que ele possa ser enchido até a boca sem derramar pela boca?

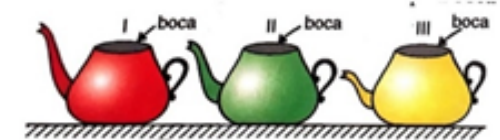

Fig. 6
a. Somente I
b. Somente II
c. Somente III

${ }^{2}$ GUIMARÃES, L. A; BOA, M. F. Mecânica. Niterói: Galera, 2010. v. 1. p. 427-433. 
3. (UNIFOR - CE) Emborca-se um tubo de ensaio em uma vasilha com água, conforme a Fig. 7. Com respeito à pressão nos pontos $a, b$, c, d, e, f qual das opções a seguir é válida?
a. $p_{a}=p_{d}$
c. $p_{e}=p_{b}$
c. $p_{a}=p_{f}$
d. $p_{c}=p_{d}$

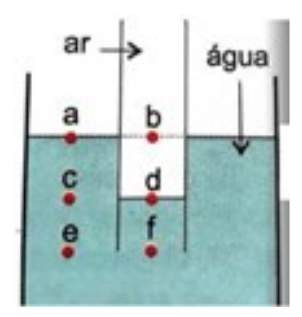

Fig. 7

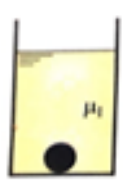

(1)

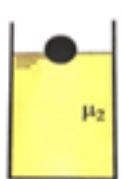

(2)

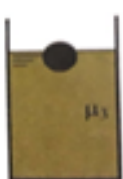

(3)
a. $\mu_{1}=\mu_{2}=\mu_{3}$
c. $\mu_{1}<\mu_{2}=\mu_{3}$
b. $\mu_{1}>\mu_{2}>\mu_{3}$
d. $\mu_{1}<\mu_{3}<\mu$

Fig. 8 